\title{
Short Communication PTEN status in advanced colorectal cancer treated with cetuximab
}

\author{
FV Negri*,1,5, C Bozzetti ${ }^{1,5}$, CA Lagrasta ${ }^{2}$, P Crafa $^{2}$, MP Bonasoni ${ }^{3}$, R Camisa', G Pedrazzi ${ }^{4}$ and A Ardizzoni ${ }^{1}$ \\ 'Medical Oncology Unit, University Hospital, Parma, Italy; ${ }^{2}$ Pathology Department, University Hospital, Parma, Italy; ${ }^{3}$ Pathology Department, Arcispedale \\ 'S. Maria Nuova', Reggio Emilia, Italy; ${ }^{4}$ Department of Public Health, University of Parma, Parma, Italy
}

BACKGROUND: LOSS of phosphatase and tensin homologue deleted in chromosome 10 (PTEN) function in advanced colorectal cancer (CRC) may represent one of the resistance mechanisms to cetuximab by interfering with the epidermal growth factor receptor signal transduction pathway.

METHODS: PTEN expression tested by indirect immunofluorescence was evaluated both on primary $(n=43)$ and on metastatic $(n=24)$ sites in CRC patients treated with cetuximab.

RESULTS: The loss of PTEN expression tested on metastatic sites was negatively associated with response (I00\% progressive disease (PD) in PTEN-negative cases vs 30\% PD in PTEN-positive cases; $P<0.05)$, PFS (0.8 vs 8.2 months; $P<0.00$ I) and OS $(2.9$ vs 14.2 months; $P<0.001$ ).

CONCLUSION: A potential role of PTEN in the anti-tumour activity of cetuximab could be hypothesised.

British Journal of Cancer (2010) 1 02, I62-164. doi:I0.1038/sj.bjc.660547I www.bjcancer.com

Published online I December 2009

(c) 2010 Cancer Research UK

Keywords: PTEN; colorectal cancer; cetuximab

Among patients with advanced colorectal cancer (CRC), a small subgroup seems to benefit from the epidermal growth factor receptor (EGFR) inhibitor, cetuximab (Cunningham et al, 2004; Saltz et al, 2004). An optimal response to EGFR inhibitors requires the EGFR-activated intracellular signal transduction pathway to be intact (Ciardiello and Tortora, 2008). Epidermal growth factor receptor-dependent cancer cells may escape from cetuximab inhibition by using alternative pathways (Viloria-Petit et al, 2001) or through a continuous activation of downstream intracellular signalling (Bianco et al, 2003).

Phosphatase and tensin homologue deleted in chromosome 10 (PTEN) is an important tumour-suppressor gene that negatively regulates Akt activities (Stambolic et al, 1998). Loss of PTEN function has been reported in CRC (Thomas and Grandis, 2004) and may represent one of the resistance mechanisms interfering with the response to EGFR antagonists by dissociating EGFR inhibition from the downstream phosphatdylinositol 3-kinase/Akt pathway (Baselga, 2001).

\section{MATERIALS AND METHODS}

Our experience refers to $50 \mathrm{mCRC}$ patients submitted both to the evaluation of PTEN and pAKT expression by indirect

*Correspondence: Dr FV Negri, Medical Oncology Unit, University Hospital, Via Gramsci 14, Parma 43100, Italy;

E-mail: francescanegri2@hotmail.com

${ }^{5}$ These authors contributed equally to this work.

Received 14 August 2009; revised 21 October 2009; accepted 9 November 2009; published online I December 2009 immunofluorescence (IFI) and to PTEN and EGFR gene copy number assessments by fluorescence in situ hybridisation (FISH). Phosphatase and tensin homologue deleted in chromosome 10 and pAKT IFI assessments were performed on $4-\mu \mathrm{m}$-thick tissue sections of paraffin-embedded specimens by using a PTEN rabbit monoclonal antibody (Millipore, Billerica, MA, USA) and a pAKT (Ser 473) rabbit monoclonal antibody (Cell Signaling Technology, Beverly, MA, USA), respectively, followed by FITC-conjugated specific secondary antibody (Sigma-Aldrich Corp., St Louis, MO, USA). Indirect immunofluorescence-positive tumour cells were recognised by bisbenzimide (Hoechst 33258) (Sigma-Aldrich Corp.) and images were obtained by fluorescent microscopy (Olympus BX41, Olympus, Inc., Melville, NY, USA). Fluorescence intensity was scored as absent, weak, moderate and strong. For both PTEN and pAKT, the percentage of cells expressing antigens was determined by evaluating the number of positive cells in a field with reference to the total number of cells in that field. Samples with an absent or weak expression in $<10 \%$ of cells were considered as negative.

Phosphatase and tensin homologue deleted in chromosome 10 copy number status assessment was performed on $4-\mu \mathrm{m}$ paraffinembedded sections using a hybridisation solution containing both a rhodamine-conjugated probe that is specific for the PTEN locus on chromosome 10q23.21 and a FITC-conjugated control probe specific for 10p11.1 - q11.1 (LSI PTEN/CEP10 - Vysis Inc., Downers Grove, IL, USA). Nuclei were counterstained with DAPI for viewing on an Olympus MX60 fluorescence microscope with a $100-\mathrm{W}$ mercury lamp. Separate narrow band pass filters were used for the detection of Spectrum Orange, Spectrum Green and DAPI. Hemizygous deletion of PTEN was defined as $>20 \%$ of tumour nuclei containing one PTEN locus signal and by the presence of CEP10 signals. Homozygous deletion of PTEN was 

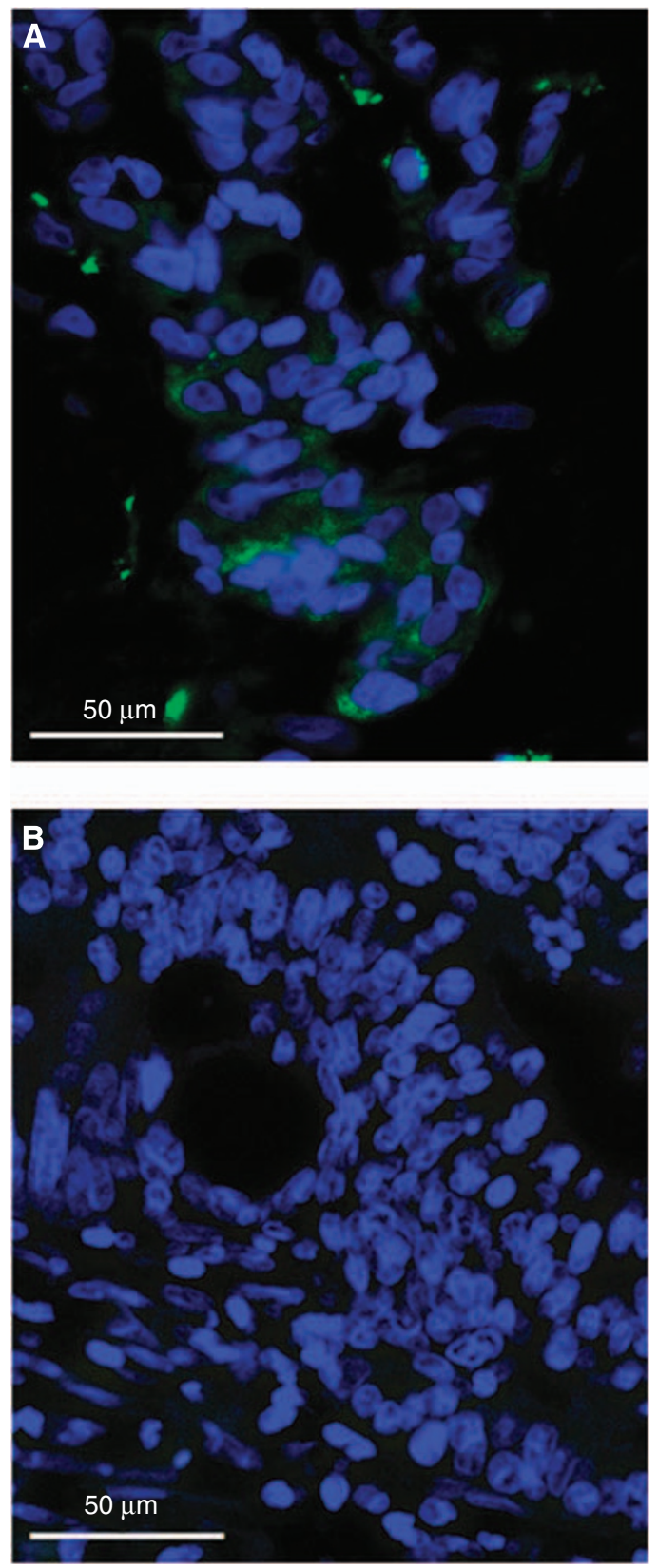

Figure I PTEN protein expression by immunofluorescence in CRC cells. (A) Positive (green) cytoplasmic staining. (B) Negative staining. Scale bar $=50 \mu \mathrm{m}$.

Table I PTEN IFI on primary tumours and metastases and response to treatment

\begin{tabular}{|c|c|c|c|c|c|c|}
\hline & \multicolumn{3}{|c|}{$\begin{array}{l}\text { Primary tumours } \\
\quad(n=43)\end{array}$} & \multicolumn{3}{|c|}{$\begin{array}{c}\text { Metastases } \\
(n=24)\end{array}$} \\
\hline & $\begin{array}{c}\text { Responders } \\
n(\%)\end{array}$ & $\begin{array}{c}\text { Non- } \\
\text { responders } \\
n(\%)\end{array}$ & $P$-value & $\begin{array}{c}\text { Responders } \\
n(\%)\end{array}$ & $\begin{array}{c}\text { Non- } \\
\text { responders } \\
n(\%)\end{array}$ & $P$-value \\
\hline $\begin{array}{l}\text { PTEN negative } \\
\text { PTEN positive }\end{array}$ & $\begin{array}{r}1(20) \\
21(55)\end{array}$ & $\begin{array}{r}4(80) \\
17(45)\end{array}$ & 0.185 & $\begin{array}{l}0(0) \\
14(70)\end{array}$ & $\begin{array}{l}4(100) \\
6(30)\end{array}$ & 0.02 \\
\hline
\end{tabular}

Abbreviations: PTEN = phosphatase and tensin homologue deleted in chromosome IO; IFI = indirect immunofluorescence. exhibited by the simultaneous lack of both PTEN locus signals and by the presence of control signals in $>30 \%$ of cells (Yoshimoto et al, 2007).

Epidermal growth factor receptor FISH was performed using the LSI EGFR Spectrum Orange/CEP 7 Spectrum Green probe set (Vysis), and counterstaining and viewing were performed as described above for the PTEN gene. An increased EGFR gene copy number was defined as the presence of three or more signals per nucleus (Moroni et al, 2005).

\section{RESULTS}

Of the patients, $80 \%$ ( 40 out of 50 ) received $\geqslant 3$ lines of chemotherapy. A total of 36 patients were treated with cetuximab and irinotecan and 14 with cetuximab and oxaliplatin. Patients who obtained a partial response (PR) or a stable disease (SD) were defined as responders. In all, 12 patients $(24 \%)$ experienced PR, $14(28 \%)$ experienced SD and $24(48 \%)$ experienced a progressive disease (PD). At a median follow-up of 23 months, 49 patients $(98 \%)$ progressed and $40(80 \%)$ died. In the whole group, median PFS and OS were 4.0 and 9.3 months, respectively.

Phosphatase and tensin homologue deleted in chromosome 10-positive staining was mainly localised to the cytoplasm of CRC cells. An example of a PTEN-positive CRC is shown in Figure 1a and a PTEN-negative CRC in Figure 1b. In all, 5 out of 43 (12\%) of the evaluable primary tumours, and 4 out of $24(17 \%)$ of the metastases were PTEN IFI negative. The loss of PTEN expression tested on metastatic sites was negatively associated with response (100\% PD in PTEN-negative cases vs $30 \%$ PD in PTEN-positive cases; $P<0.05)$ (Table 1$)$, PFS (0.8 vs 8.2 months; $P<0.001)$ and OS (2.9 vs 14.2 months; $P<0.001)$. Of the paired primary tumours and matched metastases, 25\% (5 out of 20) were discordant for PTEN expression. Hemozygous deletion of PTEN was present in 33\% (15 out of 45) of primary tumours and all of these had an absent or weak protein expression $(P<0.005)$. The PTEN FISH assessed on primary tumour was neither predictive nor prognostic. No correlation was found between PTEN FISH and PTEN expression on metastatic sites probably because of the low number of cases $(n=17)$. PAKT was not predictive of response, PFS and OS, neither was EGFR.

\section{DISCUSSION}

According to the data obtained by Loupakis et al (2009), who evaluated PTEN expression by IHC, we found a significant correlation between PTEN tested by IFI on metastatic sites and response and PFS. Moreover, in our data, PTEN also predicted OS. However, given the small number of cases, our results may deserve further validation in a wider cohort.

In our series, $25 \%$ (5 out of 20) of cases showed a PTEN primary tumour vs metastasis discordance. As recently reported by Molinari et al (2009), our observation confirms that primary CRC and paired metastasis may exhibit a difference with respect to the EGFR pathway; therefore, the analysis of metastatic sites should be considered, given that PTEN assessed on primary tumour might incompletely predict the response.

Epidermal growth factor receptor protein expression is no longer considered as selection criteria for cetuximab sensitivity (Cunningham et al, 2004; Saltz et al, 2004; Chung et al, 2005), and the mechanism of cetuximab's anti-tumour activity remains a fundamental question to be clearly addressed. A possible functional interaction of PTEN activity with EGFR tyrosine kinase signalling and a potential role for PTEN in the anti-tumour activity of cetuximab could be hypothesised. 


\section{REFERENCES}

Baselga J (2001) The EGFR as a target for anticancer therapy: focus on cetuximab. Eur J Cancer 37(Suppl 4): S16-S22

Bianco R, Shin I, Ritter CA, Yakes FM, Basso A, Rosen N, Tsurutani J, Dennis PA, Mills GB, Arteaga CL (2003) Loss of PTEN/MMAC1/TEP in EGF receptor-expressing tumor cells counteracts the antitumor action of EGFR tyrosine kinase inhibitors. Oncogene 22: 2812-2822

Chung KY, Shia J, Kemeny NE, Shah M, Schwartz GK, Tse A, Hamilton A, Pan D, Schrag D, Schwartz L, Klimstra DS, Fridman D, Kelsen DP, Saltz LB (2005) Cetuximab shows activity in colorectal cancer patients with tumors that do not express the epidermal growth factor receptor by immunohistochemistry. J Clin Oncol 23: 1803-1810

Ciardiello F, Tortora G (2008) EGFR antagonists in cancer treatment. $N$ Engl J Med 358: $1160-1174$

Cunningham D, Humblet Y, Siena S, Khayat D, Bleiberg H, Santoro A, Bets D, Mueser M, Harstrick A, Verslype C, Chau I, Van Cutsem E (2004) Cetuximab monotherapy and cetuximab plus irinotecan in irinotecanrefractory metastatic colorectal cancer. $N$ Engl J Med 351: $337-345$

Loupakis F, Pollina L, Stasi I, Ruzzo A, Scartozzi M, Santini D, Masi G, Graziano F, Cremolini C, Rulli E, Canestrari E, Funel N, Schiavon G, Petrini I, Magnani M, Tonini G, Campani D, Floriani I, Cascinu S, Falcone A (2009) PTEN expression and KRAS mutations on primary tumors and metastases in the prediction of benefit from cetuximab plus irinotecan for patients with metastatic colorectal cancer. J Clin Oncol 27: $2622-2629$

Molinari F, Martin V, Saletti P, De Dosso S, Spitale A, Camponovo A, Bordoni A, Crippa S, Mazzucchelli L, Frattini M (2009) Differing deregulation of EGFR and downstream proteins in primary colorectal cancer and related metastatic sites may be clinically relevant. Br J Cancer 100: $1087-1094$

Moroni M, Veronese S, Benvenuti S, Marrapese G, Sartore-Bianchi A, Di Nicolantonio F, Gambacorta M, Siena S, Bardelli A (2005) Gene copy number for epidermal growth factor receptor (EGFR) and clinical response to antiEGFR treatment in colorectal cancer: a cohort study. Lancet Oncol 6: 279-286, doi:10.1016/S1470-2045 (05)70102-9

Saltz LB, Meropol NJ, Loehrer Sr PJ, Needle MN, Kopit J, Mayer RJ (2004) Phase II trial of cetuximab in patients with refractory colorectal cancer that expresses the epidermal growth factor receptor. J Clin Oncol 22: $1201-1208$

Stambolic V, Suzuki A, de la Pompa JL, Brothers GM, Mirtsos C, Sasaki T, Ruland J, Penninger JM, Siderovski DP, Mak TW (1998) Negative regulation of $\mathrm{PKB} / \mathrm{AKT}$-dependent cell survival by tumor suppressor PTEN. Cell 95: 29-39

Thomas SM, Grandis JR (2004) Pharmacokinetic and pharmacodynamic properties of EGFR inhibitors under clinical investigation. Cancer Treat Rev 30: $255-268$

Viloria-Petit A, Crombet T, Jothy S, Hicklin D, Bohlen P, Schlaeppi JM, Rak J, Kerbel RS (2001) Acquired resistance to the antitumor effect of epidermal growth factor receptor-blocking antibodies in vivo: a role for altered tumor angiogenesis. Cancer Res 61: 5090-5101

Yoshimoto M, Cunha IW, Coudry RA, Fonseca FP, Torres CH, Soares FA, Squire JA (2007) FISH analysis of 107 prostate cancers shows that PTEN genomic deletion is associated with poor clinical outcome. $\mathrm{Br} J$ Cancer 97: $678-685$ 